\title{
Journal of the International AIDS

\section{Cost-effectiveness and budget impact of lopinavir/ritonavir and atazanavir plus ritonavir regimens based on 48-week results from the CASTLE study} KN Simpson*1, R Rajagopalan ${ }^{2}$ and B Dietz ${ }^{3}$

\author{
Address: ${ }^{1}$ Medical University of South Carolina, Charleston, USA, ${ }^{2}$ Abbott Health Economics and Outcomes Research, Abbott Park, USA and \\ ${ }^{3}$ Abbott GmbH \& Co, Ludwigshafen, Germany \\ * Corresponding author
}

\author{
from Ninth International Congress on Drug Therapy in HIV Infection \\ Glasgow, UK. 9-13 November 2008 \\ Published: 10 November 2008 \\ Journal of the International AIDS Society 2008, I I(SuppI I):P3 I I doi:I0.II I86/I758-2652-I I-SI-P3 I I
}

This abstract is available from: http://www.jiasociety.org/content/I I/SI/P3 I I

(c) 2008 Simpson et al; licensee BioMed Central Ltd.

\section{Purpose of the study}

The CASTLE study showed no significant differences in the percent of patients with viral load $<, 50$ copies $/ \mathrm{ml}$ or in CD4+ T-cell count increase at 48 weeks for the two antiretroviral (ARV) treatment regimens. Total cholesterol (TC) levels were elevated in $18 \%$ and $7 \%$ of patients receiving lopinavir/ritonavir (LPV/r) and atazanavir plus ritonavir (ATV+RTV) respectively. However, the economic impact of these findings is not known. The purpose of this study was to conduct a CEA and budget impact analysis comparing LPV/r and ATV+RTV for a group of antiretroviral-naïve patients with a baseline CD4+ T-cell distribution and TC profile similar to the CASTLE population.

\section{Methods}

This decision analysis study used a previously published Markov model of HIV disease, incorporating coronary heart disease (CHD) events to compare the short- and long-term budget impacts and CHD consequences expected for the two regimens.

\section{Summary of results}

The basic assumption was a baseline CHD risk of $4.6 \%$ and that $50 \%$ of the population in the CASTLE study were smokers. The CHD risk differences in favor of ATV+RTV resulted in an average improvement in life expectancy of 0.031 QALYs ( 11 days), and an incremental cost-effectiveness ratio of $\$ 1,409,734 / \mathrm{QALY}$. Use of the $\mathrm{LPV} / \mathrm{r}$ regimen saved $\$ 24,518$ and $\$ 36,651$ at 5 and 10 years, respec- tively, with lifetime cost savings estimated at $\$ 38,490$. A sensitivity analysis using a cohort of all smokers on antihypertensive medication estimated the TC difference between the regimens at 48 weeks resulting in an average improvement in life expectancy of 0.088 QALYs (32 days) in favor of ATV+RTV, and cost-effectiveness ratio of $\$ 520,861 /$ QALY.

\section{Conclusion}

The use of an ATV+RTV-based regimen in ARV-naïve patients with a CHD risk similar to patients in the CASTLE study is not a cost-effective use of scarce resources. The very small added CHD risk incurred by $\mathrm{LPV} / \mathrm{r}$ treatment is more than offset by its short- and long-term cost savings. 